\title{
Research on the Development of Rural Sports Under the Strategy of Rural Revitalization
}

\author{
Zhi hong Yin \\ Physical Education Institute, Nanchang Institute of Technology, NanChang, China \\ e-mail:964012041@qq.com
}

\begin{abstract}
This article through the literature material law, questionnaire survey method, comparative method and other research methods, the rural left-behind children physical exercise situation investigation, physical exercise behavior research, to their sports participation present situation, physical exercise interest, exercise attitude and motivation research, analysis of rural left-behind children sports conditions and deficiencies. Through investigation and research, it is demonstrated that the participation rate of left-behind children in sports is not high, their interest in physical exercise is not strong enough, and their cognition of sports is not comprehensive. It is suggested that government guarantee should be strengthened, school physical exercise environment should be improved and family tasks should be clarified to build a mechanism to help rural left-behind children carry out physical exercise, build a good sports environment for them and promote their healthy growth.
\end{abstract}

Keywords-Rural sports; sports development; countermeasures

\section{INTRODUCTION}

With the development of the times and the rapid development of society and economy in our country, the gap between urban and rural areas is getting wider and wider. Rural decline has become an indisputable fact. Therefore, empty nest villages, villages for the elderly, villages for left-behind children and impoverished villages have appeared. The 19th National Congress of the Communist Party of China put the strategy of rural revitalization on the agenda as a national strategy, and clarified the goals and tasks of specific rural revitalization actions, which shows that it attaches great importance to it. As a national strategy, rural revitalization is related to whether our country can fundamentally solve the problems of urban-rural differences, unbalanced and insufficient rural development. In 2020, there will be $61,025,500$ left-behind children in rural areas, accounting for $21.88 \%$ of the country's children. How to protect the rights and interests of left-behind children in rural areas is one of the important tasks of governments at all levels, and it is also an important responsibility of every family. For left-behind children's schools, physical education teachers and teaching facilities are seriously inadequate. Emphasis on cultural courses and neglect of physical education have become the norm, which will lead to imbalances in children's education, resulting in poor physical fitness, slow development and unhealthy physical fitness of left-behind children And other phenomena. In-depth understanding of the existing problems in the physical exercise of left-behind children, the status quo of children's physical exercise, and abundant physical activities are conducive to improving the physical fitness, mental health and good social adaptability of left-behind children. Researching and analyzing the status quo of rural sports development will help government departments to formulate more effective policies and systems. In order to provide rural left-behind children with a more comprehensive and better education, the goals will be clearer, which will help promote the vigorous development of rural sports. ${ }^{[1]}$ Physical education is indispensable to the growth of children. Due to the incompleteness of school physical education work, children' $\mathrm{s}$ understanding of physical education is not comprehensive enough, and children' $s$ interest in physical education is greatly reduced. Only by increasing their understanding of physical education, In this way, it is easier for us to help them, improve their awareness of sports, and let them have a more comprehensive understanding of sports activities. Secondly, most of the research directions for left-behind children are related to sociology, psychology, and demography. There are relatively few researches in the direction of sports, so more sports research is needed to promote social sports. Perfect research. ${ }^{[1]}$ 


\section{RESEARCH OBJECTS AND METHODS}

\subsection{Research objects}

Taking the rural compulsory education students in Lushan City, Jiangxi Province as the research object, and the left-behind children from Grade 1 to Grade 6 in Liaonan Primary School and Huaqiao Primary School as the research objects, 130 students ( 32 from Grade 1 to Grade 3, 29 from Grade 4, 33 from Grade 5 and 36 from Grade 6) were randomly investigated.

\subsection{Research methods}

\subsubsection{Documentation}

Using China National Knowledge Infrastructure (CNKI), the keywords of "rural left-behind children," "physical exercise," "physical education of left-behind children," and "rural sports development," 20 articles were searched for data collation, and some books on "social sports," "school sports," and "sports psychology," were read in the library to view the basic information and basic status of sports activities of left-behind children.

\subsection{Questionnaire surveymethod}

According to the content of the study, the questionnaire was designed to investigate and analyze the participation of physical exercise, the cognition of sports, the degree of interest in sports activities, the motivation of participating in physical exercise, the content and place of sports activities inside and outside the school, and the psychological activities of sports. 130 questionnaires were distributed and 120 were recovered, of which 118 were valid, with an effective rate of $91 \%$.

\subsection{Mathematical statistics}

SPSS software was used for statistical processing and analysis of the collected data.

\section{RESEARCH PROCESS AND ANALYSIS}

\subsection{Investigation and Analysis on Sports Activities of Rural Left-behind Children}

\subsubsection{Project survey of left-behind children keen to participate in sports activities}

According to Table 1, it can be seen that the sports activities that left-behind children are keen to participate in are relatively easy to carry out. Among them, the number of table tennis and badminton projects is relatively large, because these two projects require simple venues, easy to carry out, strong interest, and do not need to be too professional. Both men and women are more suitable, and these two projects can be carried out only by two people, especially badminton. Badminton does not require high venues, and it can be carried out in an empty space. In basketball and football, the skills and rules of these projects are relatively high, and the number of people who need to participate will be more. Generally, football and basketball are mostly boys, while skipping rope and jumping skin tendon are relatively simple, but most of them are girls. Taekwondo and Latin dance are relatively new sports. However, due to the high skill and professional requirements of these sports, it takes time to learn and pay special attention to study to master them. Therefore, there are fewer people who are keen to participate. Studies have shown that for rural left-behind children, due to poor physical exercise conditions and less investment in sports, simple sports venues and equipment will be more preferred, and simple and easy to operate sports become the preferred choice of left-behind children. ${ }^{[2]}$

TABLE 1 CONTENTS OF LEFT-BEHIND CHILDREN 'S PARTICIPATION IN SPORTS ACTIVITIES ( $\mathrm{N}=118$ )

\begin{tabular}{c|c|c}
\hline & head & proportion \\
\hline Basketball & 26 & 22.03 \\
\hline football & 17 & 14.4 \\
\hline ping-pong ball & 49 & 41.52 \\
\hline Badminton & 32 & 27.11 \\
\hline Taekwondo & 4 & 3.38 \\
\hline Shuttlecock & 16 & 13.55 \\
\hline Rope Jump & 19 & 16.1 \\
\hline Skin Jump & 25 & 21.18 \\
\hline Running & 8 & 6.77 \\
\hline Latin Dance & 2 & 1.69 \\
\hline
\end{tabular}

\subsubsection{Investigation on places where left-behind children participate in sports activities}

Sports venues is an important guarantee for rural leftbehind children to participate in sports activities, and it is also one of the main factors affecting the number of leftbehind children ' $\mathrm{s}$ sports activities and projects. The survey shows that there are mainly four places to participate in sports activities. (1) ' Home small and medium-sized hospitals ' are sports venues; (2) ' Village sports venues ' for physical exercise venues; (3) Taking ' vacant land near home ' as a place for physical exercise; (4) Physical exercise in school playgrounds. According to the review, most left-behind children tend to choose extracurricular sports venues near their homes, followed by the choice of public sports facilities in the village for exercise, but there are few people to exercise in the formal places of sports consumption. Therefore, most parents and children believe that physical exercise should not be spent, and these parents are more willing to spend money on cultural courses, which will eliminate the enthusiasm of children for physical exercise and the balance and comprehensiveness of physical development. 


\subsection{Subjective cognition survey on rural left- behind children's participation in sports}

\subsubsection{Cognition of left-behind children on the function of sports activities}

Table 2 shows that children have the highest level of awareness of the function that sports can change physique and enhance health, accounting for 66.1 per cent of the total, but the awareness of other functions of sports is not ideal, especially sports that can exercise and develop brain thinking, stimulate potential and increase physical and mental pleasure. There are also children who believe that exercise is harmful to health and waste of time and other functional cognition is not clear, but these problems such as waste of time, vulnerability and damage to health are also objective. Therefore, schools and families should correctly guide students to carry out sports activities, develop good exercise habits and form a correct attitude towards physical exercise ${ }^{[3]}$

TABLE 2 SPORTS COGNITIVE STATUS OF LEFT-BEHIND CHILDREN $(\mathrm{N}=118)$

\begin{tabular}{l|c|c}
\hline Content & number & proportion \\
\hline $\begin{array}{l}\text { Sports can change physique and } \\
\text { enhance health }\end{array}$ & 78 & 66.1 \\
\hline $\begin{array}{l}\text { Sports can develop brain } \\
\text { thinking and stimulate potential }\end{array}$ & 20 & 16.9 \\
\hline $\begin{array}{l}\text { Sports can promote interpersonal } \\
\text { communication }\end{array}$ & 38 & 32.2 \\
\hline $\begin{array}{l}\text { Sport increases physical and } \\
\text { mental pleasure }\end{array}$ & 41 & 34.7 \\
\hline $\begin{array}{l}\text { Physical exercise impairs health } \\
\text { and fatigue }\end{array}$ & 20 & 16.9 \\
\hline $\begin{array}{l}\text { Sports waste time and hinder } \\
\text { learning }\end{array}$ & 32 & 27.1 \\
\hline $\begin{array}{l}\text { Sport can develop willpower and } \\
\text { cooperation }\end{array}$ & 27 & 22.9 \\
\hline
\end{tabular}

\subsection{2 urvey of left-behind children 's interest in sports}

The interest degree of rural left-behind children in sports is the driving force for them to participate in physical exercise. The survey shows that $43.22 \%$ of the total are very interested in and relatively interested in physical exercise, nearly half of them, which is not ideal in general. Children in primary schools are in the stage of playing, and their interest in sports is still not strong enough. This phenomenon is caused by many factors, such as the absence of parents of left-behind children in rural areas, the lack of parental support, the lack of guidance of family environment, the lack of sports venues and facilities, the influence of the surrounding physical exercise atmosphere, the insufficient attention to school physical education, and the lack of school resources. Therefore, whether in the family or school can not ignore how to cultivate children ' $\mathrm{s}$ interest in physical exercise this problem, as far as possible to improve children ' $\mathrm{s}$ interest in physical exercise.3.2.3 Motivation of leftbehind children to participate in sports activities

\subsubsection{Motivation of left-behind children to participate in sports activities}

Table 3 shows that most of the children exercise to exercise and relieve stress, and this result is also imaginable. The proportion of relieving stress is the highest in the percentage, accounting for $66.94 \%$, indicating that the students in the primary school stage have relatively high learning pressure. Most of them are in the cultural class when they go to school. They have more homework after class and higher pressure. Through physical exercise, students can release this tension and pressure. However, there are many motivations for participating in physical exercise, and it is also important to cultivate cooperation ability, willpower and improve sports performance, especially cooperation ability and willpower, which will greatly help them to participate in social work. After all, sports can cultivate children's spirit of hard work, tenacious struggle and mutual cooperation, which is recognized by all sectors of society. Now, the physical education curriculum examination throughout the country is included in the high school entrance examination. The proportion of children 's motivation to participate in exercise learning skills is still the least, which may be due to the lack of interest in the project or interest but no empty time to learn, or interested in the project withoutprofessional people to guide. On the whole, their motivation to participate in physical exercise is relatively comprehensive, or to exercise and relieve pressure. ${ }^{[4]}$

TABLE 3 MotiVATION OF LEFT-BEHIND CHILDREN TO PARTICIPATE IN SPORTS

\begin{tabular}{l|c|c}
\hline Category & People & proportion \\
\hline Physical exercise & 72 & 61.01 \\
\hline relaxation of emotions & 57 & 48.3 \\
\hline relieving stress & 79 & 66.94 \\
\hline enriching life & 13 & 11.01 \\
\hline cultivating cooperative spirit & 16 & 13.55 \\
\hline satisfying hobbies & 24 & 20.33 \\
\hline learning skills & 8 & 6.77 \\
\hline $\begin{array}{l}\text { and improving sports } \\
\text { performance }\end{array}$ & 45 & 38.13 \\
\hline
\end{tabular}

\subsubsection{Analysis of Factors Affecting Middle School Students ' Participation in Physical Exercise}

The results show that Lushan City middle school students weekly exercise frequency is very small, many students are addicted to the network, games and other aspects, reduce the time of sports activities. On the one hand, it takes a lot of time and energy to study. On the other hand, it is mainly related to the lack of school sports 
venues and sports facilities. Some school holiday sports venues and sports equipment are not open to students, resulting in students' physical activity is obviously insufficient

Table 4 Statistics of students' daily exercise time and weekly exercise frequency

\begin{tabular}{c|c|c|c|c|c|c}
\hline hour & total num ber & propor tion & number of boys & propor tion & numb er of girls & proport ion \\
\hline 0 & 176 & $45.1 \%$ & 58 & $14.9 \%$ & 118 & $30.2 \%$ \\
\hline $0.5-1$ & 83 & $21.3 \%$ & 50 & $12.8 \%$ & 33 & $8.5 \%$ \\
\hline $1-2$ & 63 & $16.2 \%$ & 33 & $8.5 \%$ & 30 & $7.7 \%$ \\
\hline $2-3$ & 68 & $17.4 \%$ & 57 & $14.5 \%$ & 11 & $2.9 \%$ \\
\hline
\end{tabular}

\subsection{Rural left-behind children to participate in sports support mechanism}

\subsubsection{Strengthen government guarantees to create conditions for physical exercise for left- behind children}

In order to enhance the support mechanism of rural left-behind children' s sports activities, the government should formulate some relevant policies in accordance with the actual situation, which can ensure that the migrant parents can work safely and better protect the physical and mental health development of left-behind children. This is also a social security for them. In terms of educational policies, it is necessary to protect the right of left-behind children to receive education, and to ensure the comprehensive development of children' s education, especially cultural knowledge education and physical education. It is necessary to adjust educational policies in time according to the actual situation, improve the quality of education and teaching, and require schools to regularly organize sports activities. It can also let the elderly who stay in the village to care for left - behind children understand sports knowledge and pay attention to children 's physical exercise.

\subsubsection{Defining the Responsibility of Family Subjects to Develop Children 's Exercise Habits}

In fact, parents are the best witnesses of children' $\mathrm{s}$ growth and the best learning model for children. However, with China' s economic development, most farmers are reluctant to choose to leave their children and work in other cities for the sake of life' s difficulty, while other people' s care for children is not enough. Therefore, as guardians, they should assume the responsibilities of education, care and concern for left-behind children. Even if they cannot be around, and the current communication tools are also relatively developed. Parents can learn about children' $s$ recent situation by video or phone in empty hours, and understand children' s recent learning status, and can buy some sports equipment online. Go home to buy some suitable for children ' s sports equipment, with them to learn sports knowledge, remind children in learning empty time more exercise, to relax themselves, develop long-term stability, good physical exercise habits: ${ }^{[5]}$

\subsubsection{Improving the school environment to increase children' $s$ interest in participating in sports}

School is one of the most important places for leftbehind children to engage in sports, and it is also a place where they can be guaranteed by sports. The age of 6 to 15 is an important period for left-behind children to form a world outlook, values and outlook on life. Schools should cultivate children' $s$ interest in sports and help them establish a correct concept of sports. Schools can organize a variety of sports activities, such as sports games and competitions. These sports activities can also better shape the excellent personality of left-behind children. Left-behind children will have a series of psychological problems because their parents are not around, such as timidity and inferiority, and fear of contacting people. To solve this problem, the school invests some funds to set up psychological counseling centers to help children solve these problems. Every teacher in the school must master the ability to solve children ' s psychological problems and maintain the physical and mental growth of left-behind children. ${ }^{[5]}$

\section{ConClusions}

Through investigation: the lack of school sports facilities in Lushan City, the backwardness of physical education teachers, the school's insufficient attention to physical education, and the lack of a good family environment for left-behind children and the correct guidance of parents, resulting in a relatively reduced opportunity for left-behind children in rural areas to participate in sports, Their interest in sports has declined, and many reasons have led to their unsatisfactory participation in physical exercise. Second: Left-behind children have insufficient subjective cognition of sports. Left-behind children's cognition of sports only rests on the surface of strengthening their health and exercising. For sports, they can cultivate willpower and cooperation skills, promote interpersonal relationships, and cultivate The quality of will is not sufficiently understood, and some teachers, parents and children may even think that physical exercise is a waste of time, hinders learning, and 
physical exercise is easily injured. The reason for this idea is that they have not been properly guided and have not really Understand sports and understand that sports play an important role in their lives. Furthermore: left-behind children lack interest in sports and lack of comprehensive motivation. Most children's interest in sports is only average, and some even have no interest. This situation is not optimistic enough. The childhood stage is at the stage of playfulness. If the team If the interest in sports is not strong, it is easy to be attracted by other things, and gradually get away from sports. Moreover, the motivation of left-behind children to participate in sports is generally to exercise and relieve stress, such as how to improve sports performance, study skills, and develop teamwork. These motives also require a certain understanding of them, so how to go It is very important for them to understand the real sports, and let them understand the real charm of sports.

For children, schools may be an important place for them to study physical education seriously. First of all, schools should follow the provisions of the "New Curriculum Standards" to ensure the number of physical education hours and improve the quality of the curriculum while ensuring the number of physical education hours. In my spare time, I can carry out some sports-related activities, and organize some class basketball games, football matches, etc., to mobilize the enthusiasm of leftbehind children's participation in sports. In normal school hours, teachers can organize more sports-related games and actively encourage For children's participation, it is possible to develop some interesting and easy methods for children to master motor skills, adjust the classroom atmosphere at any time, observe children's performance in the classroom anytime and anywhere, and correct their bad behaviors in time. Weekend schools can also develop some extracurricular sports culture Activities to enrich their after-school life and allow them to better improve them, because parents are not at home and lack of caring brings inferiority and loneliness, relieve their miss of their parents, exercise their physical fitness, and enhance the friendship and friendship between them. The relationship with teachers, through such an environment, slowly promotes the psychological growth of children, allows them to develop a better character, and improves their physical and mental health.

Parents are the only support for left-behind children, and they are a role model for left-behind children to learn from. In fact, with permission, parents can try to change the guardianship mode of their children. The impact of the family education environment is very important for the physical and mental health of the left-behind children, and if one of the parents can stay at home to take care of the children's single-parent guardianship The model is the best way for children to grow up. Guardians of left-behind children must take on the responsibility and obligation of education, care, and care for children, pay attention to their children' $s$ learning emotions and emotions, and encourage their children to take more physical exercises. But in fact, many rural parents take physical exercises. They are all opposed, because they have not formed a real awareness of sports health and feel that it is not necessary. Therefore, we should first help the parents of left-behind children to establish a correct view of sports, let them change their prejudice against sports, and let them understand that physical and mental health is very important, and children's physical and mental health education should be put in the first place. If parents do not understand this aspect of sports, they can communicate with the school teachers at any time. The school should help the parents of left-behind children understand sports at any time. After all, the relationship between children's parents and left-behind children is very close. They guide left-behind children to understand the effect of sports. Better than school teachers, supervise children to learn. If the guardian is not present, parents should regularly communicate with their children via video to understand the recent school situation of the left-behind children, and guide and supervise the children to learn about sports.

\section{REFERENCES}

[1] Luyuan Town. Sports Sociology [M]. Beijing : Higher Education Press, 2001 : 55

[2] Yang Wenxuan, Yang Ting. Introduction to sports [M], Beijing: Higher Education Press, 2005.

[3] General textbooks for sports colleges. Sports psychology [M]. Beijing: Higher Education Press, 2006, 6: 159-161.

[4] Wang Shihu, Zhang Benjun. Research on the current situation of left-behind children' s sports and its support mechanism [A]. Journal of Chaohu University, 2015, 17 (3), $1672-2868$.

[5] Xu Wanbin. Study on the Current Situation of Sports Psychology of Left-behind Children and Its Support Mechanism [A]. Sports Time and Space, 1009-9328 (2016) 10-040-01. 